\title{
Rhinovirus Biology, Antigenic Diversity, and Advancements in the Design of a Human Rhinovirus Vaccine
}

\author{
Christopher C. Stobart ${ }^{1 *}$, Jenna M. Nosek ${ }^{1}$ and Martin L. Moore ${ }^{2,3 *}$ \\ 1 Department of Biological Sciences, Butler University, Indianapolis, IN, United States, ${ }^{2}$ Department of Pediatrics, Emory \\ University, Atlanta, GA, United States, ${ }^{3}$ Children's Healthcare of Atlanta, Atlanta, GA, United States
}

OPEN ACCESS

Edited by:

Gary McLean,

Imperial College London, United Kingdom

Reviewed by: Benny Chain,

University College London, United Kingdom Hemant Kumar Vyas,

TESARO, Inc., United States Nathan Wylie Bartlett, University of Newcastle, Australia

${ }^{*}$ Correspondence: Martin L. Moore martin.moore@emory.edu Christopher C. Stobart cstobart@butler.edu

Specialty section:

This article was submitted to Infectious Diseases,

a section of the journal

Frontiers in Microbiology

Received: 31 August 2017 Accepted: 21 November 2017 Published: 05 December 2017

Citation:

Stobart CC, Nosek JM and Moore ML (2017) Rhinovirus Biology, Antigenic Diversity, and Advancements in the Design of a Human Rhinovirus Vaccine.

Front. Microbiol. 8:2412. doi: 10.3389/fmicb.2017.02412
Human rhinovirus (HRV) remains a leading cause of several human diseases including the common cold. Despite considerable research over the last 60 years, development of an effective vaccine to HRV has been viewed by many as unfeasible due, in part, to the antigenic diversity of circulating HRVs in nature. Over 150 antigenically distinct types of HRV are currently known which span three species: HRV A, HRV B, and HRV C. Early attempts to develop a rhinovirus vaccine have shown that inactivated HRV is capable of serving as a strong immunogen and inducing neutralizing antibodies. Yet, limitations to virus preparation and recovery, continued identification of antigenic variants of $\mathrm{HRV}$, and logistical challenges pertaining to preparing a polyvalent preparation of the magnitude required for true efficacy against circulating rhinoviruses continue to prove a daunting challenge. In this review, we describe HRV biology, antigenic diversity, and past and present advances in HRV vaccine design.

Keywords: rhinovirus, vaccine, common cold, respiratory disease, viral diversity

\section{INTRODUCTION}

Human rhinoviruses (HRVs) are respiratory viruses that belong to the family Picornaviridae and genus Enterovirus. HRVs were first isolated in the 1950s and remain the leading cause of upper respiratory tract infections worldwide (Price, 1956; Jacobs et al., 2013). HRV remains the primary etiologic agent of the common cold and is responsible for significant morbidity, medical costs, and absences from school and the workplace (Fendrick et al., 2003; Pappas et al., 2008; Gern, 2010; van der Zalm et al., 2011; Jacobs et al., 2013). Annual economic costs associated with HRV infections are likely to exceed 60 billion dollars per year (Fendrick et al., 2003). HRV infections occur year-round and in all parts of the world and exhibit seasonality, peaking during the spring and/or autumn (Winther et al., 2006; Miller et al., 2007; Jacobs et al., 2013; Litwin and Bosley, 2014; Leotte et al., 2017). In addition to causing upper respiratory infections, HRV has also been linked to development and shown to exacerbate asthma and lower respiratory tract infections in human asthmatic volunteers (Hicks et al., 2006; Malmstrom et al., 2006; Renwick et al., 2007; Jackson et al., 2008, 2014; Message et al., 2008; Gern, 2010; Jacobs et al., 2013; Saraya et al., 2014). The significant health burden associated with HRV continues to highlight the dire need for an HRV vaccine. Yet, several challenges have precluded efficacious vaccine development. 


\section{HRV INFECTIONS AND DISEASE}

Rhinoviruses are among the most common viral infectious agents found in humans. HRVs account for more then 50\% of upper respiratory tract infections and infection rates among young children can be as high as 8-12 times a year (Arruda et al., 1995; Turner, 1997; Pappas et al., 2008). HRV infections are generally associated with an incubation period of 2 days followed by a symptomatic period of 1 to 2 weeks before clearance (Pappas et al., 2008). Asymptomatic infections of the nasopharynx are quite common for rhinoviruses, especially among young children (van Benten et al., 2003; Iwane et al., 2011). Upper respiratory tract infections are associated with common cold-like symptoms including rhinorrhea, sore throat, coughing, sneezing, nasal congestion, and general malaise (Arruda et al., 1997; Jacobs et al., 2013). In addition to the common cold, rhinovirus infections are often linked to acute otitis media and rhinosinusitis, which also frequently coincide with bacterial coinfection (Pitkaranta et al., 1997; Alper et al., 2007; Jackson et al., 2008; Jacobs et al., 2013). Despite an optimal temperature for HRV replication in the cooler surfaces $\left(32-33^{\circ} \mathrm{C}\right)$ of the upper respiratory tract, rhinoviruses are also implicated with lower respiratory diseases including pneumonia, bronchitis, and bronchiolitis, and exacerbation of asthma (McFadden et al., 1985; Turner, 1997; Papadopoulos et al., 2000; Renwick et al., 2007; Gern, 2010). Over half of all asthma exacerbation incidents are known to be associated with HRV infections and early HRV infections resulting in wheezing promote a greater risk of asthma development later in life (Gern and Busse, 1999; Gern et al., 1999; Hayden, 2004; Jackson et al., 2008; Dougherty and Fahy, 2009). Approximately, 90\% of children hospitalized with acute asthma attacks were shown to have detectable HRV (Bizzintino et al., 2011). Furthermore, a study evaluating 3 to 18 -year-old patients admitted with wheezing identified nearly half tested positive for HRV (Heymann et al., 2004). Collectively, these studies demonstrate that HRV, though not typically considered a pathogen of high mortality, has a high potential for acute respiratory illness and the potential to promote or exacerbate chronic respiratory health conditions.

Transmission of HRVs occurs primarily between individuals by either direct contact, contact with fomites, or aerosols (Gwaltney and Hendley, 1978; Gwaltney et al., 1978; Dick et al., 1987; Jennings and Dick, 1987; Hendley and Gwaltney, 1988). Rhinoviruses are capable of remaining infectious on surfaces outside of hosts for hours resulting in a high potential for spread between infected and uninfected individuals (Hendley et al., 1973). Susceptibility to severe infection and re-infections has been linked to many environmental and genetic factors including poor interferon responses, existing allergies or asthma, exposure to air pollutants including tobacco smoke, poor diet, and stress (Gern, 2010; Kang et al., 2012; Jacobs et al., 2013). Rates of reinfection with specific types of HRV suggest that in some cases of HRV infection, competent immunity failed to develop or that pre-existing immunity cannot be maintained (Papi et al., 2006).

\section{HRV STRUCTURE AND BIOLOGY}

Human rhinovirus is a non-enveloped virus with a positivesense single-stranded RNA (+ssRNA) of approximately $7.2 \mathrm{~kb}$ that encodes 11 proteins (Figure 1A) (Palmenberg et al., 2009, 2010; Palmenberg and Gern, 2015). The viral capsid of HRV is comprised of four viral proteins (VPs): VP1, VP2, VP3, and VP4. The remaining viral proteins are responsible for viral replication and subsequent assembly. Antigenic variation among HRV types is derived from variations in the exposed surface of VP1, VP2, and VP3, while embedded VP4 is responsible for RNA packaging during assembly (Figure 1B). Compared to the rest of the HRV genome, the capsid proteins exhibit a high degree of heterogeneity resulting in a wide range of antigenic diversity (Glanville and Johnston, 2015; Lewis-Rogers et al., 2017). Several antigenic sites have been identified for HRV strains through study of binding of neutralizing antibodies. However, the locations of these sites are often not conserved (Sherry and Rueckert, 1985; Sherry et al., 1986; Appleyard et al., 1990).

VP1 mediates cell surface attachment through engagement of a variety of cell surface receptors (Figure 1C) (Palmenberg and Gern, 2015; Blaas, 2016). Traditionally, the majority of HRV types were known to bind the intercellular adhesion molecule 1 (ICAM-1) receptor and a minority of HRV types utilized the low-density lipoprotein receptor (LDLR) for binding (Staunton et al., 1989; Hofer et al., 1994; Palmenberg, 2017). However, with the recent identification of a specific variant of cadherinrelated family member $3(\mathrm{CDHR} 3)$ as the primary receptor for HRV C species and the breadth of circulating HRV types, yetto-be identified receptors may also exist (Bochkov et al., 2015, 2016; Palmenberg, 2017). HRV may enter the cell through several pathways including macropinocytosis and clathrin-dependent and clathrin-independent endocytosis (Blaas, 2016). Upon entry and uncoating, the viral genome is translated and subsequently proteolytically processed by virus-encoded proteases, $2 \mathrm{~A}$ and $3 \mathrm{C}$ (Fuchs and Blaas, 2010). During virion assembly and genomic packaging, 60 units of each capsid protein associate, with 1 unit of each capsid protein per face, to form the icosahedral structure encapsulating the RNA genome of the virus (Rossmann et al., 1985; Palmenberg et al., 2010; Liu et al., 2016).

\section{PHYLOGENETIC DIVERSITY OF RHINOVIRUSES}

Three species of rhinovirus are currently known: HRV-A, HRV$B$, and HRV-C. However, sequencing and serologic methods have defined approximately $83 \mathrm{HRV}$-A types, $32 \mathrm{HRV}$-B types, and 55 $\mathrm{HRV}-\mathrm{C}$ types with potentially as many as 150 to 170 serological distinct HRV types in circulation (Figure 1C) (Palmenberg et al., 2009; McIntyre et al., 2013). Rhinovirus strains within a given species share greater than $70 \%$ amino acid identity and new types are classified almost exclusively now based on VP1 or VP4/VP2 sequence alignments (Palmenberg and Gern, 2015). Isolates which share greater than $87 \%$ identity may be merged with existing types (McIntyre et al., 2013; Palmenberg and Gern, 2015). A major challenge to the development of an HRV 




FIGURE 1 | Human rhinovirus genomic organization, virion structure, and species. (A) The $7.21 \mathrm{~kb}+\mathrm{SsRNA}$ genome of HRV-16 is comprised of a single open-reading frame encoding 11 gene products, which upon translation into three distinct polyproteins are cleaved by HRV-encoded proteases (2A and $3 \mathrm{C}$ ). The $5^{\prime}$-end of the genome is capped with a short viral priming protein (VPg) for incorporation during virion assembly and a the $3^{\prime}$-end is polyadenylated. Capsid proteins VP1 and VP4 $\left(^{*}\right)$ are generally used for phylogenetic analysis. RdRP, RNA-dependent RNA polymerase; UTR, untranslated region. (B) An icosahedral virion structure of HRV with a pentamer structure shown highlighting the external capsid proteins (VP1, VP2, and VP3) organization. VP1 is responsible for receptor engagement and VP4 is located beneath each monomeric unit and is responsible for genomic association with VPg. (C) Three distinct species of human rhinovirus have been identified (HRV-A, HRV-B, and HRV-C). The approximate number of types within each species classification and known receptors of each are shown.

vaccine and subsequent establishment of protective immunity is the phylogenetic breadth of existing HRV serotypes. Infection with one type of HRV is unlikely to afford any immunity to other types resulting in lifelong infections to different HRV type exposures. However, limited cross-serotype protection has been demonstrated for some closely-related types (Cooney et al., 1973; Glanville and Johnston, 2015). Among known types of HRV, HRV-A, and HRV-C are generally associated with more severe disease and asthma exacerbations than HRV-B (Miller et al., 2009; Piralla et al., 2009; Bochkov et al., 2011; Lee et al., 2012, 2016). Structures of all three species exhibit distinct surface pocket differences which may account for their phenotypic differences (Palmenberg and Gern, 2015; Liu et al., 2016).

\section{RECENT DISCOVERY AND BIOLOGY OF HRV-C}

HRV-C was recently identified in 2006 and has since been recognized as a major contributor to HRV disease (Arden et al., 2006; Lamson et al., 2006; Kistler et al., 2007; Renwick et al., 2007; Dominguez et al., 2008). Over half of all HRV infections in young infants are now recognized as HRV-C strains (Bochkov et al., 2011). Furthermore, among HRV types detected during childhood acute asthma episodes, HRV-C was the more frequently detected species (Bizzintino et al., 2011). Following their initial identification, nearly 60 types have been identified and they have now been classified as a distinct species of HRV from HRV-A and HRV-B (Simmonds et al., 2010; McIntyre et al., 2013; Palmenberg and Gern, 2015). However, unlike HRV-A and HRV-B, study of HRV-C strains has been complicated by the inability to initially grow these viruses in cell culture.

The first report to describe successful recovery of an HRVC type (C15) via reverse genetics was in 2011, however these viruses could not be subsequently passaged (Bochkov et al., 2011). Unlike its counterparts, HRV-C types do not use ICAM1 or LDLR as a primary receptor for attachment (Bochkov et al., 2011). Phenotypically, HRV-C may be more tolerable of higher temperatures for replication resulting in more lower respiratory tract disease than species A or B (Ashraf et al., 2013). Furthermore, the virus could not be readily passaged or cultured until the recent identification of CDHR3 as a primary receptor of the virus in 2015 (Bochkov et al., 2015). The first capsid structure of an HRV-C type soon followed (Liu et al., 2016). Combined with a now cultivable reverse genetics approach, considerable attention is being given to study HRV-C biology. Recent work has shown that HRV-C selectively targets ciliated airway epithelial cells which express CDHR3 (Griggs et al., 2017). These findings are encouraging and pave the way for more thorough study of HRV-C biology and potential development of HRV-C-specific antivirals and vaccines. Due to its significant role in human disease, development of an effective rhinovirus vaccine for the common cold will need to include antigenic coverage from representative $\mathrm{HRV}-\mathrm{C}$ strains. 


\section{CHALLENGES TO DESIGN OF HRV VACCINES}

Development of a vaccine for rhinovirus remains a universal hope of the public health and scientific communities. For over a half century, the prospect of developing an HRV vaccine has remained bleak. There remain many technical, logistical, and fundamental biological challenges to developing a successful vaccine for HRV. Mice and cottons rats are important models for testing of efficacy of vaccines to elicit neutralizing antibodies, however, they are not fully permissive to infection and can only resemble some aspects of HRV pathogenesis in humans (Bartlett et al., 2008; Blanco et al., 2014a). Recent advances in producing mice that are transgenic for human ICAM-1 have made them an improved model for study of HRV infection (Bartlett et al., 2008). Yet, any vaccine preparation would likely have to be studied directly in humans.

Unlike many other human viral pathogens, the shear breadth of serologically distinct types of HRV presents a unique and difficult challenge to vaccine design. In order to develop an HRV vaccine, regardless of approach (e.g., live-attenuated, inactivated), one or more vaccination preparations must be able to elicit protective neutralizing antibodies to potentially over 150 serologically distinct types spanning three different species. Despite advances in cell culture resulting in increased titers of virus, the shear technical challenge of producing sufficient quantity and quality of antigen to cover the breadth of HRV types remains a key technical challenge. In addition, there remains insufficient surveillance and epidemiologic data to accurately identify which specific dominant HRV-A and HRVC types to prioritize in vaccine preparations to mitigate disease. Furthermore, several studies using both antivirals, antigenic peptide preparations, and virus have reported the induction of escape mutations, often with a single amino acid (Heinz et al., 1989; Appleyard et al., 1990; Speller et al., 1993). However, the structure of the majority of HRV types have yet to be resolved and only recently has the first HRV-C structure been determined (Liu et al., 2016). Despite these clear challenges, there have been advances in understanding how to develop an HRV vaccine and the feasibility of inducing lasting protective immunity.

\section{PAST AND CURRENT VACCINE EFFORTS}

By the 1960s, it became evident that many serologically distinct strains of rhinovirus existed and that development of a polyvalent vaccine preparation would be required to combat the common cold (Mitchison, 1965). Early attempts to develop an HRV vaccine during the 1960 and 1970s focused on: (1) whether live-attenuated or inactivated HRV strains induced antibodies and were capable of affording protection; (2) if heterologous or divergent strains could induce broad protection and lastly, (3) if multivalent vaccine preparations could be efficacious. A study by Bynoe et al. (1961) demonstrated that individuals were capable of having protective levels of antisera to a specific strain of HRV. Two follow-up studies published in 1963 demonstrated that a single strain of either live-unattenuated HRV, or HRV inactivated by formalin or heat, was capable of inducing antibodies following intramuscular injection and that circulating antibody levels correlated inversely with associated illness (Doggett et al., 1963; Mufson et al., 1963). By Mitchison (1965), it was evident that vaccination with a strain of HRV was capable of not only inducing protective antibodies, but also may provide homologous protection to the same strain. Subsequent studies published over the next few years supported that HRV vaccines could be efficacious with lasting immunity following homologous challenge, but not with heterologous strains (Perkins et al., 1969a,b; Buscho et al., 1972).

In the early 1970s, the first studies evaluating crossneutralization and serologic reactivity between many HRV types were published which opened the door for the earliest attempts at polyvalent vaccine preparations. Cooney et al. (1973) demonstrated that rabbit antisera to 37 types resulted in limited cross-neutralization between at least five types. These studies and earlier studies using monovalent preparations led to the first major attempt at a polyvalent vaccine for HRV in Hamory et al. (1975). By this time, 89 HRV types had been described and several others were in varying stages of confirmation. In this study, Hamory et al. (1975) produced two separate decavalant HRV vaccine preparations by combining 10 formalin-inactivating unique sets of types with initial titers of $10^{1.5}-10^{6.0} \mathrm{TCID}_{50} / \mathrm{mL}$. Unfortunately, these vaccine preparations resulted in low titers of neutralizing antibodies with detectable host responses to less than $40 \%$ of input types. Compared to the known number of types at the time, development of an effective polyvalent vaccine was soon regarded as improbable or impossible (Fox, 1976; Couch, 1984).

Over the next 30 years, scientific advances in cellular and molecular biology and continued research on HRV biology and type-specific differences led to renewed interest and hope in development of an HRV vaccine. The first capsid HRV crystal structure (HRV-14) was resolved in Rossmann et al. (1985). Structures of all three species of HRV would soon be determined with over 70 structures now deposited in the protein data bank (PDB) (Palmenberg, 2017). In Palmenberg et al. $(2009,2010)$, full genomic sequences were published for a significant number of known HRV-A and HRV-B strains, which provided new insight into HRV evolution, specific-strain differences, and strong evidence for recombination of antigenic types.

In light of the daunting task of developing a polyvalent inactivated vaccine preparation to over 100 types and advances in understanding HRV structure, recent efforts have focused on identifying and exploiting conserved antigenic sites through subunit and/or T-cell based approaches. Several recent attempts using VP1 as an immunogen have demonstrated that crossserotype reactive antibodies can be generated with enough exposure and recombinant VP1 may be a potential antigen for induction of limited cross-reactivity (Edlmayr et al., 2011; McLean et al., 2012). Furthermore, studies have also shown that N-terminus of VP4 is capable of eliciting cross-serotype antibodies (Katpally et al., 2009; Panjwani et al., 2016). Efforts in the field of influenza have shown that promoting recognition 
and immunity based on internal epitopes expressed to $\mathrm{T}$ cells can be effective at targeting more conserved epitopes and afford greater Th1 activity and cross-serotype protection (Lee et al., 2008; Hillaire et al., 2011). Earlier studies with HRV have demonstrated that $\mathrm{T}$ cell populations recognize both shared and type specific epitopes (Hastings et al., 1993a,b; Gern et al., 1997). Expression of a recombinant VP0 in combination with a Th1-focused adjuvant (combination of incomplete Fruend's and $\mathrm{CpG}$ ) was effective at promoting strong Th1-specific crossserotype antibody responses (Glanville et al., 2013). These collective studies provide demonstrate that development of a subunit vaccine may be an effective approach to addressing HRV antigenic diversity in a vaccine preparation. In addition, these studies illustrate that cross-reactive antigens (with the use of specific adjuvants) may be used to increase serological breadth of HRV coverage while limiting the number of types of antigens necessary.

Efforts examining whole virus preparations continue to be used to explore the potential for vaccine preparations. In Blanco et al. (2014b), intramuscular administration with live HRV-16 was shown to induce cross-serotype neutralizing antibody responses after intranasal challenge in cotton rats. Last year, a 50-valent inactivated vaccine preparation comprised of types representative of the diversity of known HRV-A strains was shown to induce neutralizing antibodies to all but one type tested following boost in rhesus macaques (Lee et al., 2016). This study by Lee et al. (2016) also demonstrated using a reconstituted 1975 decavalent vaccine preparation from the Hamory et al. (1975) study, that the pitfall to this early polyvalent vaccine effort was likely a combination of inadequate antigen levels and the potential need for an adjuvant. These recent findings illustrated that a high valency in polyvalent vaccine preparations, as would likely be necessary in an HRV vaccine, may be effective at promoting

\section{REFERENCES}

Alper, C. M., Winther, B., Mandel, E. M., and Doyle, W. J. (2007). Temporal relationships for cold-like illnesses and otitis media in sibling pairs. Pediatr. Infect. Dis. J. 26, 778-781. doi: 10.1097/INF.0b013e31812 4 aa31

Appleyard, G., Russell, S. M., Clarke, B. E., Speller, S. A., Trowbridge, M., and Vadolas, J. (1990). Neutralization epitopes of human rhinovirus type 2. J. Gen. Virol. 71(Pt 6), 1275-1282. doi: 10.1099/0022-1317-71-6-1275

Arden, K. E., McErlean, P., Nissen, M. D., Sloots, T. P., and Mackay, I. M. (2006). Frequent detection of human rhinoviruses, paramyxoviruses, coronaviruses, and bocavirus during acute respiratory tract infections. J. Med. Virol. 78, 1232-1240. doi: 10.1002/jmv.20689

Arruda, E., Boyle, T. R., Winther, B., Pevear, D. C., Gwaltney, J. M. Jr., and Hayden, F. G. (1995). Localization of human rhinovirus replication in the upper respiratory tract by in situ hybridization. J. Infect. Dis. 171, 1329-1333. doi: 10.1093/infdis/171.5.1329

Arruda, E., Pitkaranta, A., Witek, T. J. Jr., Doyle, C. A., and Hayden, F. G. (1997). Frequency and natural history of rhinovirus infections in adults during autumn. J. Clin. Microbiol. 35, 2864-2868.

Ashraf, S., Brockman-Schneider, R., Bochkov, Y. A., Pasic, T. R., and Gern, J. E. (2013). Biological characteristics and propagation of human rhinovirus-C in differentiated sinus epithelial cells. Virology 436, 143-149. doi: 10.1016/j.virol. 2012.11.002 lasting immunity provided that sufficient antigen levels are present.

\section{CLOSING THOUGHTS: THE FUTURE POTENTIAL FOR AN HRV VACCINE}

For much of the last century, an HRV vaccine was often regarded as impossible. A multivalent vaccine preparation for any pathogen with the valency necessary to afford protection for circulating HRV has yet to be demonstrated in any commercial vaccine. Yet, advances in our understanding of HRV types, capsid structure, and recent advances in identifying conserved crossreactive antigenic sites have shed new light on directions to explore in vaccine design. Furthermore, advances in HRV reverse genetics and the potential to create chimeric virus preparations collectively suggest that development of an HRV vaccine is not technically impossible, but will require novel ingenuity and continued study of existing similarities and differences among HRV types.

\section{AUTHOR CONTRIBUTIONS}

Contributed directly to the writing and drafting, editing, and final approval of the article before submission CS, JN, and MM.

\section{ACKNOWLEDGMENTS}

This work was supported by funding from a Holcomb Awards Committee (HAC) Faculty Research Grant (CS), the Butler University Department of Biological Sciences, and faculty startup funding (CS) from Butler University.

Bartlett, N. W., Walton, R. P., Edwards, M. R., Aniscenko, J., Caramori, G., Zhu, J., et al. (2008). Mouse models of rhinovirus-induced disease and exacerbation of allergic airway inflammation. Nat. Med. 14, 199-204. doi: 10.1038/nm1713

Bizzintino, J., Lee, W. M., Laing, I. A., Vang, F., Pappas, T., Zhang, G., et al. (2011). Association between human rhinovirus $C$ and severity of acute asthma in children. Eur. Respir. J. 37, 1037-1042. doi: 10.1183/09031936.00092410

Blaas, D. (2016). Viral entry pathways: the example of common cold viruses. Wien. Med. Wochenschr. 166, 211-226. doi: 10.1007/s10354-016-0461-2

Blanco, J. C., Boukhvalova, M. S., Perez, D. R., Vogel, S. N., and Kajon, A. (2014a). Modeling human respiratory viral infections in the cotton rat (Sigmodon hispidus). J. Antivir. Antiretrovir. 6, 40-42. doi: 10.4172/jaa.1000093

Blanco, J. C., Core, S., Pletneva, L. M., March, T. H., Boukhvalova, M. S., and Kajon, A. E. (2014b). Prophylactic antibody treatment and intramuscular immunization reduce infectious human rhinovirus 16 load in the lower respiratory tract of challenged cotton rats. Trials Vaccinol. 3, 52-60. doi: 10.1016/j.trivac.2014.02.003

Bochkov, Y. A., Palmenberg, A. C., Lee, W. M., Rathe, J. A., Amineva, S. P., Sun, X., et al. (2011). Molecular modeling, organ culture and reverse genetics for a newly identified human rhinovirus C. Nat. Med. 17, 627-632. doi: 10.1038/nm. 2358

Bochkov, Y. A., Watters, K., Ashraf, S., Griggs, T. F., Devries, M. K., Jackson, D. J., et al. (2015). Cadherin-related family member 3, a childhood asthma susceptibility gene product, mediates rhinovirus $\mathrm{C}$ binding and replication. Proc. Natl. Acad. Sci. U.S.A. 112, 5485-5490. doi: 10.1073/pnas.1421178112 
Bochkov, Y. A., Watters, K., Basnet, S., Sijapati, S., Hill, M., Palmenberg, A. C., et al. (2016). Mutations in VP1 and 3A proteins improve binding and replication of rhinovirus C15 in HeLa-E8 cells. Virology 499, 350-360. doi: 10.1016/j.virol. 2016.09.025

Buscho, R. F., Perkins, J. C., Knopf, H. L., Kapikian, A. Z., and Chanock, R. M. (1972). Further characterization of the local respiratory tract antibody response induced by intranasal instillation of inactivated rhinovirus 13 vaccine. J. Immunol. 108, 169-177.

Bynoe, M. L., Hobson, D., Horner, J., Kipps, A., Schild, G. C., and Tyrrell, D. A. (1961). Inoculation of human volunteers with a strain of virus isolated from a common cold. Lancet 1, 1194-1196. doi: 10.1016/S0140-6736(61)91 941-9

Cooney, M. K., Kenny, G. E., Tam, R., and Fox, J. P. (1973). Cross relationships among 37 rhinoviruses demonstrated by virus neutralization with potent monotypic rabbit antisera. Infect. Immun. 7, 335-340.

Couch, R. B. (1984). The common cold: control? J. Infect. Dis. 150, 167-173. doi: 10.1093/infdis/150.2.167

Dick, E. C., Jennings, L. C., Mink, K. A., Wartgow, C. D., and Inhorn, S. L. (1987). Aerosol transmission of rhinovirus colds. J. Infect. Dis. 156, 442-448. doi: 10.1093/infdis/156.3.442

Doggett, J. E., Bynoe, M. L., and Tyrrell, D. A. (1963). Some attempts to produce an experimental vaccine with rhinoviruses. Br. Med. J. 1, 34-36. doi: 10.1136/bmj. 1.5322 .34

Dominguez, S. R., Briese, T., Palacios, G., Hui, J., Villari, J., Kapoor, V., et al. (2008). Multiplex MassTag-PCR for respiratory pathogens in pediatric nasopharyngeal washes negative by conventional diagnostic testing shows a high prevalence of viruses belonging to a newly recognized rhinovirus clade. J. Clin. Virol. 43, 219-222. doi: 10.1016/j.jcv.2008.06.007

Dougherty, R. H., and Fahy, J. V. (2009). Acute exacerbations of asthma: epidemiology, biology and the exacerbation-prone phenotype. Clin. Exp. Allergy 39, 193-202. doi: 10.1111/j.1365-2222.2008.03157.x

Edlmayr, J., Niespodziana, K., Popow-Kraupp, T., Krzyzanek, V., Focke-Tejkl, M., Blaas, D., et al. (2011). Antibodies induced with recombinant VP1 from human rhinovirus exhibit cross-neutralisation. Eur. Respir. J. 37, 44-52. doi: 10.1183/ 09031936.00149109

Fendrick, A. M., Monto, A. S., Nightengale, B., and Sarnes, M. (2003). The economic burden of non-influenza-related viral respiratory tract infection in the United States. Arch. Intern. Med. 163, 487-494. doi: 10.1001/archinte.163. 4.487

Fox, J. P. (1976). Is a rhinovirus vaccine possible? Am. J. Epidemiol. 103, 345-354. doi: 10.1093/oxfordjournals.aje.a112233

Fuchs, R., and Blaas, D. (2010). Uncoating of human rhinoviruses. Rev. Med. Virol. 20, 281-297. doi: 10.1002/rmv.654

Gern, J. E. (2010). The ABCs of rhinoviruses, wheezing, and asthma. J. Virol. 84, 7418-7426. doi: 10.1128/JVI.02290-09

Gern, J. E., and Busse, W. W. (1999). Association of rhinovirus infections with asthma. Clin. Microbiol. Rev. 12, 9-18.

Gern, J. E., Dick, E. C., Kelly, E. A., Vrtis, R., and Klein, B. (1997). Rhinovirusspecific $\mathrm{T}$ cells recognize both shared and serotype-restricted viral epitopes. J. Infect. Dis. 175, 1108-1114. doi: 10.1086/516449

Gern, J. E., Lemanske, R. F. Jr., and Busse, W. W. (1999). Early life origins of asthma. J. Clin. Invest. 104, 837-843. doi: 10.1172/JCI8272

Glanville, N., and Johnston, S. L. (2015). Challenges in developing a cross-serotype rhinovirus vaccine. Curr. Opin. Virol. 11, 83-88. doi: 10.1016/j.coviro.2015. 03.004

Glanville, N., McLean, G. R., Guy, B., Lecouturier, V., Berry, C., Girerd, Y., et al. (2013). Cross-serotype immunity induced by immunization with a conserved rhinovirus capsid protein. PLOS Pathog. 9:e1003669. doi: 10.1371/journal.ppat. 1003669

Griggs, T. F., Bochkov, Y. A., Basnet, S., Pasic, T. R., Brockman-Schneider, R. A., Palmenberg, A. C., et al. (2017). Rhinovirus C targets ciliated airway epithelial cells. Respir Res 18:84. doi: 10.1186/s12931-017-0567-0

Gwaltney, J. M. Jr., and Hendley, J. O. (1978). Rhinovirus transmission: one if by air, two if by hand. Am. J. Epidemiol. 107, 357-361. doi: 10.1093/oxfordjournals. aje.a112555

Gwaltney, J. M. Jr., Moskalski, P. B., and Hendley, J. O. (1978). Hand-to-hand transmission of rhinovirus colds. Ann. Intern. Med. 88, 463-467. doi: 10.7326/ 0003-4819-88-4-463
Hamory, B. H., Hamparian, V. V., Conant, R. M., and Gwaltney, J. M. Jr. (1975). Human responses to two decavalent rhinovirus vaccines. J. Infect. Dis. 132, 623-629. doi: 10.1093/infdis/132.6.623

Hastings, G. Z., Francis, M. J., Rowlands, D. J., and Chain, B. M. (1993a). Antigen processing and presentation of human rhinovirus to CD4 T cells is facilitated by binding to cellular receptors for virus. Eur. J. Immunol. 23, 1340-1345. doi: $10.1002 /$ eji.1830230623

Hastings, G. Z., Francis, M. J., Rowlands, D. J., and Chain, B. M. (1993b). Epitope analysis of the $\mathrm{T}$ cell response to a complex antigen: proliferative responses to human rhinovirus capsids. Eur. J. Immunol. 23, 2300-2305. doi: 10.1002/eji. 1830230937

Hayden, F. G. (2004). Rhinovirus and the lower respiratory tract. Rev. Med. Virol. 14, 17-31. doi: 10.1002/rmv.406

Heinz, B. A., Rueckert, R. R., Shepard, D. A., Dutko, F. J., McKinlay, M. A., Fancher, M., et al. (1989). Genetic and molecular analyses of spontaneous mutants of human rhinovirus 14 that are resistant to an antiviral compound. J. Virol. 63, 2476-2485.

Hendley, J. O., and Gwaltney, J. M. Jr. (1988). Mechanisms of transmission of rhinovirus infections. Epidemiol. Rev. 10, 243-258. doi: 10.1093/oxfordjournals. epirev.a036024

Hendley, J. O., Wenzel, R. P., and Gwaltney, J. M. Jr. (1973). Transmission of rhinovirus colds by self-inoculation. N. Engl. J. Med. 288, 1361-1364. doi: 10.1056/NEJM197306282882601

Heymann, P. W., Carper, H. T., Murphy, D. D., Platts-Mills, T. A., Patrie, J., McLaughlin, A. P., et al. (2004). Viral infections in relation to age, atopy, and season of admission among children hospitalized for wheezing. J. Allergy Clin. Immunol. 114, 239-247. doi: 10.1016/j.jaci.2004.04.006

Hicks, L. A., Shepard, C. W., Britz, P. H., Erdman, D. D., Fischer, M., Flannery, B. L., et al. (2006). Two outbreaks of severe respiratory disease in nursing homes associated with rhinovirus. J. Am. Geriatr. Soc. 54, 284-289. doi: 10.1111/j.15325415.2005.00529.x

Hillaire, M. L., Osterhaus, A. D., and Rimmelzwaan, G. F. (2011). Induction of virus-specific cytotoxic T lymphocytes as a basis for the development of broadly protective influenza vaccines. J. Biomed. Biotechnol. 2011:939860. doi: 10.1155/ 2011/939860

Hofer, F., Gruenberger, M., Kowalski, H., Machat, H., Huettinger, M., Kuechler, E., et al. (1994). Members of the low density lipoprotein receptor family mediate cell entry of a minor-group common cold virus. Proc. Natl. Acad. Sci. U.S.A. 91, 1839-1842. doi: 10.1073/pnas.91.5.1839

Iwane, M. K., Prill, M. M., Lu, X., Miller, E. K., Edwards, K. M., Hall, C. B., et al. (2011). Human rhinovirus species associated with hospitalizations for acute respiratory illness in young US children. J. Infect. Dis. 204, 1702-1710. doi: 10.1093/infdis/jir634

Jackson, D. J., Gangnon, R. E., Evans, M. D., Roberg, K. A., Anderson, E. L., Pappas, T. E., et al. (2008). Wheezing rhinovirus illnesses in early life predict asthma development in high-risk children. Am. J. Respir. Crit. Care Med. 178, 667-672. doi: 10.1164/rccm.200802-3090C

Jackson, D. J., Makrinioti, H., Rana, B. M., Shamji, B. W., Trujillo-Torralbo, M. B., Footitt, J., et al. (2014). IL-33-dependent type 2 inflammation during rhinovirus-induced asthma exacerbations in vivo. Am. J. Respir. Crit. Care Med. 190, 1373-1382. doi: 10.1164/rccm.201406-1039OC

Jacobs, S. E., Lamson, D. M., St George, K., and Walsh, T. J. (2013). Human rhinoviruses. Clin. Microbiol. Rev. 26, 135-162. doi: 10.1128/CMR.00077-12

Jennings, L. C., and Dick, E. C. (1987). Transmission and control of rhinovirus colds. Eur. J. Epidemiol. 3, 327-335. doi: 10.1007/BF00145641

Kang, M. J., Yu, H. S., Seo, J. H., Kim, H. Y., Jung, Y. H., Kim, Y. J., et al. (2012). GSDMB/ORMDL3 variants contribute to asthma susceptibility and eosinophilmediated bronchial hyperresponsiveness. Hum. Immunol. 73, 954-959. doi: 10.1016/j.humimm.2012.06.009

Katpally, U., Fu, T. M., Freed, D. C., Casimiro, D. R., and Smith, T. J. (2009). Antibodies to the buried $\mathrm{N}$ terminus of rhinovirus VP4 exhibit cross-serotypic neutralization. J. Virol. 83, 7040-7048. doi: 10.1128/JVI.00557-09

Kistler, A., Avila, P. C., Rouskin, S., Wang, D., Ward, T., Yagi, S., et al. (2007). Pan-viral screening of respiratory tract infections in adults with and without asthma reveals unexpected human coronavirus and human rhinovirus diversity. J. Infect. Dis. 196, 817-825. doi: 10.1086/520816

Lamson, D., Renwick, N., Kapoor, V., Liu, Z., Palacios, G., Ju, J., et al. (2006). MassTag polymerase-chain-reaction detection of respiratory pathogens, 
including a new rhinovirus genotype, that caused influenza-like illness in New York State during 2004-2005. J. Infect. Dis. 194, 1398-1402. doi: 10.1086/ 508551

Lee, L. Y., Ha do, L. A., Simmons, C., de Jong, M. D., Chau, N. V., Schumacher, R., et al. (2008). Memory $\mathrm{T}$ cells established by seasonal human influenza A infection cross-react with avian influenza A (H5N1) in healthy individuals. J. Clin. Invest. 118, 3478-3490. doi: 10.1172/JCI32460

Lee, S., Nguyen, M. T., Currier, M. G., Jenkins, J. B., Strobert, E. A., Kajon, A. E., et al. (2016). A polyvalent inactivated rhinovirus vaccine is broadly immunogenic in rhesus macaques. Nat. Commun. 7:12838. doi: 10.1038/ ncomms 12838

Lee, W. M., Lemanske, R. F. Jr., Evans, M. D., Vang, F., Pappas, T., Gangnon, R., et al. (2012). Human rhinovirus species and season of infection determine illness severity. Am. J. Respir. Crit. Care Med. 186, 886-891. doi: 10.1164/rccm. 201202-0330OC

Leotte, J., Trombetta, H., Faggion, H. Z., Almeida, B. M., Nogueira, M. B., Vidal, L. R., et al. (2017). Impact and seasonality of human rhinovirus infection in hospitalized patients for two consecutive years. J. Pediatr. 93, 294-300. doi: 10.1016/j.jped.2016.07.004

Lewis-Rogers, N., Seger, J., and Adler, F. R. (2017). Human rhinovirus diversity and evolution: how strange the change from major to minor. J. Virol. 91:e01659-16. doi: 10.1128/JVI.01659-16

Litwin, C. M., and Bosley, J. G. (2014). Seasonality and prevalence of respiratory pathogens detected by multiplex PCR at a tertiary care medical center. Arch. Virol. 159, 65-72. doi: 10.1007/s00705-013-1794-4

Liu, Y., Hill, M. G., Klose, T., Chen, Z., Watters, K., Bochkov, Y. A., et al. (2016). Atomic structure of a rhinovirus C, a virus species linked to severe childhood asthma. Proc. Natl. Acad. Sci. U.S.A. 113, 8997-9002. doi: 10.1073/ pnas. 1606595113

Malmstrom, K., Pitkaranta, A., Carpen, O., Pelkonen, A., Malmberg, L. P., Turpeinen, M., et al. (2006). Human rhinovirus in bronchial epithelium of infants with recurrent respiratory symptoms. J. Allergy Clin. Immunol. 118, 591-596. doi: 10.1016/j.jaci.2006.04.032

McFadden, E. R. Jr., Pichurko, B. M., Bowman, H. F., Ingenito, E., Burns, S., Dowling, N., et al. (1985). Thermal mapping of the airways in humans. J. Appl. Physiol. 58, 564-570.

McIntyre, C. L., Knowles, N. J., and Simmonds, P. (2013). Proposals for the classification of human rhinovirus species A, B and C into genotypically assigned types. J. Gen. Virol. 94(Pt 8), 1791-1806. doi: 10.1099/vir.0.05 3686-0

McLean, G. R., Walton, R. P., Shetty, S., Peel, T. J., Paktiawal, N., Kebadze, T., et al. (2012). Rhinovirus infections and immunisation induce cross-serotype reactive antibodies to VP1. Antiviral Res. 95, 193-201. doi: 10.1016/j.antiviral.2012. 06.006

Message, S. D., Laza-Stanca, V., Mallia, P., Parker, H. L., Zhu, J., Kebadze, T., et al. (2008). Rhinovirus-induced lower respiratory illness is increased in asthma and related to virus load and Th1/2 cytokine and IL-10 production. Proc. Natl. Acad. Sci. U.S.A. 105, 13562-13567. doi: 10.1073/pnas.0804181105

Miller, E. K., Khuri-Bulos, N., Williams, J. V., Shehabi, A. A., Faouri, S., Al Jundi, I., et al. (2009). Human rhinovirus C associated with wheezing in hospitalised children in the Middle East. J. Clin. Virol. 46, 85-89. doi: 10.1016/j.jcv.2009. 06.007

Miller, E. K., Lu, X., Erdman, D. D., Poehling, K. A., Zhu, Y., Griffin, M. R., et al. (2007). Rhinovirus-associated hospitalizations in young children. J. Infect. Dis. 195, 773-781. doi: 10.1086/511821

Mitchison, D. A. (1965). Prevention of colds by vaccination against a rhinovirus: a report by the scientific committee on common cold vaccines. Br. Med. J. 1, 1344-1349. doi: 10.1136/bmj.1.5446.1344

Mufson, M. A., Ludwig, W. M., James, H. D. Jr., Gauld, L. W., Rourke, J. A., Holper, J. C., et al. (1963). Effect of neutralizing antibody on experimental rhinovirus infection. JAMA 186, 578-584. doi: 10.1001/jama.1963.6371006002 9013

Palmenberg, A. C. (2017). Rhinovirus C, asthma, and cell surface expression of virus receptor CDHR3. J. Virol. 91:e00072-17. doi: 10.1128/JVI.00072-17

Palmenberg, A. C., and Gern, J. E. (2015). Classification and evolution of human rhinoviruses. Methods Mol. Biol. 1221, 1-10. doi: 10.1007/978-1-49391571-2_1
Palmenberg, A. C., Rathe, J. A., and Liggett, S. B. (2010). Analysis of the complete genome sequences of human rhinovirus. J. Allergy Clin. Immunol. 125, 1190-1199; quiz 1200-1191. doi: 10.1016/j.jaci.2010.04.010

Palmenberg, A. C., Spiro, D., Kuzmickas, R., Wang, S., Djikeng, A., Rathe, J. A., et al. (2009). Sequencing and analyses of all known human rhinovirus genomes reveal structure and evolution. Science 324, 55-59. doi: 10.1126/science.116 5557

Panjwani, A., Asfor, A. S., and Tuthill, T. J. (2016). The conserved N-terminus of human rhinovirus capsid protein VP4 contains membrane pore-forming activity and is a target for neutralizing antibodies. J. Gen. Virol. 97, 3238-3242. doi: 10.1099/jgv.0.000629

Papadopoulos, N. G., Bates, P. J., Bardin, P. G., Papi, A., Leir, S. H., Fraenkel, D. J., et al. (2000). Rhinoviruses infect the lower airways. J. Infect. Dis. 181, 1875-1884. doi: 10.1086/315513

Papi, A., Bellettato, C. M., Braccioni, F., Romagnoli, M., Casolari, P., Caramori, G., et al. (2006). Infections and airway inflammation in chronic obstructive pulmonary disease severe exacerbations. Am. J. Respir. Crit. Care Med. 173, 1114-1121. doi: 10.1164/rccm.200506-8590C

Pappas, D. E., Hendley, J. O., Hayden, F. G., and Winther, B. (2008). Symptom profile of common colds in school-aged children. Pediatr. Infect. Dis. J. 27, 8-11. doi: 10.1097/INF.0b013e31814847d9

Perkins, J. C., Tucker, D. N., Knope, H. L., Wenzel, R. P., Hornick, R. B., Kapikian, A. Z., et al. (1969a). Evidence for protective effect of an inactivated rhinovirus vaccine administered by the nasal route. Am. J. Epidemiol. 90, 319-326. doi: 10.1093/oxfordjournals.aje.a121076

Perkins, J. C., Tucker, D. N., Knopf, H. L., Wenzel, R. P., Kapikian, A. Z., and Chanock, R. M. (1969b). Comparison of protective effect of neutralizing antibody in serum and nasal secretions in experimental rhinovirus type 13 illness. Am. J. Epidemiol. 90, 519-526. doi: 10.1093/oxfordjournals.aje.a121098

Piralla, A., Rovida, F., Campanini, G., Rognoni, V., Marchi, A., Locatelli, F., et al. (2009). Clinical severity and molecular typing of human rhinovirus C strains during a fall outbreak affecting hospitalized patients. J. Clin. Virol. 45, 311-317. doi: 10.1016/j.jcv.2009.04.016

Pitkaranta, A., Arruda, E., Malmberg, H., and Hayden, F. G. (1997). Detection of rhinovirus in sinus brushings of patients with acute community-acquired sinusitis by reverse transcription-PCR. J. Clin. Microbiol. 35, 1791-1793.

Price, W. H. (1956). The isolation of a new virus associated with respiratory clinical disease in humans. Proc. Natl. Acad. Sci. U.S.A. 42, 892-896. doi: 10.1073/pnas. 42.12.892

Renwick, N., Schweiger, B., Kapoor, V., Liu, Z., Villari, J., Bullmann, R., et al. (2007). A recently identified rhinovirus genotype is associated with severe respiratorytract infection in children in Germany. J. Infect. Dis. 196, 1754-1760. doi: 10.1086/524312

Rossmann, M. G., Arnold, E., Erickson, J. W., Frankenberger, E. A., Griffith, J. P., Hecht, H. J., et al. (1985). Structure of a human common cold virus and functional relationship to other picornaviruses. Nature 317, 145-153. doi: $10.1038 / 317145 \mathrm{a} 0$

Saraya, T., Kurai, D., Ishii, H., Ito, A., Sasaki, Y., Niwa, S., et al. (2014). Epidemiology of virus-induced asthma exacerbations: with special reference to the role of human rhinovirus. Front. Microbiol. 5:226. doi: 10.3389/fmicb.2014. 00226

Sherry, B., Mosser, A. G., Colonno, R. J., and Rueckert, R. R. (1986). Use of monoclonal antibodies to identify four neutralization immunogens on a common cold picornavirus, human rhinovirus 14. J. Virol. 57, 246-257.

Sherry, B., and Rueckert, R. (1985). Evidence for at least two dominant neutralization antigens on human rhinovirus 14. J. Virol. 53, 137-143.

Simmonds, P., McIntyre, C., Savolainen-Kopra, C., Tapparel, C., Mackay, I. M., and Hovi, T. (2010). Proposals for the classification of human rhinovirus species C into genotypically assigned types. J. Gen. Virol. 91(Pt 10), 2409-2419. doi: 10.1099/vir.0.023994-0

Speller, S. A., Sangar, D. V., Clarke, B. E., and Rowlands, D. J. (1993). The nature and spatial distribution of amino acid substitutions conferring resistance to neutralizing monoclonal antibodies in human rhinovirus type 2. J. Gen. Virol. 74(Pt 2), 193-200. doi: 10.1099/0022-1317-74-2-193

Staunton, D. E., Merluzzi, V. J., Rothlein, R., Barton, R., Marlin, S. D., and Springer, T. A. (1989). A cell adhesion molecule, ICAM-1, is the major surface receptor for rhinoviruses. Cell 56, 849-853. doi: 10.1016/0092-8674(89)90689-2 
Turner, R. B. (1997). Epidemiology, pathogenesis, and treatment of the common cold. Ann. Allergy Asthma Immunol. 78, 531-539; quiz 539-540. doi: 10.1016/ S1081-1206(10)63213-9

van Benten, I., Koopman, L., Niesters, B., Hop, W., van Middelkoop, B., de Waal, L., et al. (2003). Predominance of rhinovirus in the nose of symptomatic and asymptomatic infants. Pediatr. Allergy Immunol. 14, 363-370. doi: 10.1034/j. 1399-3038.2003.00064.x

van der Zalm, M. M., Wilbrink, B., van Ewijk, B. E., Overduin, P., Wolfs, T. F., and van der Ent, C. K. (2011). Highly frequent infections with human rhinovirus in healthy young children: a longitudinal cohort study. J. Clin. Virol. 52, 317-320. doi: 10.1016/j.jcv.2011.09.003

Winther, B., Hayden, F. G., and Hendley, J. O. (2006). Picornavirus infections in children diagnosed by RT-PCR during longitudinal surveillance with weekly sampling: association with symptomatic illness and effect of season. J. Med. Virol. 78, 644-650. doi: 10.1002/jmv.20588
Conflict of Interest Statement: MM co-founded Meissa Vaccines, Inc., and serves as the chief scientific officer for the company. MM is an inventor in a patent application (PCT/US2016/037658) describing a rhinovirus vaccine described herein.

The other authors declare that the research was conducted in the absence of any commercial or financial relationships that could be construed as a potential conflict of interest.

Copyright (c) 2017 Stobart, Nosek and Moore. This is an open-access article distributed under the terms of the Creative Commons Attribution License (CC BY).

The use, distribution or reproduction in other forums is permitted, provided the original author(s) or licensor are credited and that the original publication in this journal is cited, in accordance with accepted academic practice. No use, distribution or reproduction is permitted which does not comply with these terms. 